\title{
Paic: o pioneirismo no processo de avaliação municipal com autonomia
}

\author{
CLÁUDIO DE ALBUQUERQUE MARQUES*
}

ANA PAULA DE MEDEIROS RIBEIRO**

MARIA ISABEL FILGUEIRAS LIMA CIASCA***

\section{RESUMO}

Este artigo tem como principal objetivo apresentar as atividades desenvolvidas pelo Programa Alfabetização na Idade Certa (Paic), especificamente no eixo de Avaliação, durante o ano de 2007, na busca de cumprir com uma de suas metas prioritárias: ajudar os municípios cearenses a implantar sistemas municipais de avaliação. A estratégia desse programa foi iniciar as atividades pela avaliação dos alunos, buscando criar um ambiente em que o próprio município conduziria todo o processo de forma autônoma e, conseqüentemente, tendo condiçóes para conhecer a realidade não apenas da educação municipal como também de todos os seus alunos, individualmente. Dessa forma, o artigo traz a metodologia utilizada na elaboração do instrumental que compôs o protocolo de avaliação de 2007, bem como as açóes inovadoras desenvolvidas no que se refere à divulgação dos resultados. As conseqüências esperadas das açóes

\footnotetext{
* Professor Ajunto do Departamento de Fundamentos da Educação e Coordenador de Planejamento e Avaliação de Programas e Açóes Acadêmicas da Universidade Federal do Ceará (marquesclaudio@yahoo.com).

** Doutoranda do Programa de Pós-graduação em Educação Brasileira da Universidade Federal do Ceará (apaulaufc@hotmail.com).

*** Professora Ajunta do Departamento de Fundamentos da Educação e Vice-diretora da Faculdade de Educação da Universidade Federal do Ceará (isabelfil@uol.com.br).
} 
do programa já começaram a ser detectadas por meio do grande compromisso e envolvimento dos municípios no decorrer de todo o processo de avaliaçâo e, sobretudo, de intervençấo na busca de melhorias na qualidade da educação.

Palavras-chave: alfabetização, avaliação de desempenho, qualidade do ensino, Programa Alfabetização na Idade Certa (Paic).

\section{RESUMEN}

Este artículo tiene como principal objetivo presentar las actividades desarrolladas por el Programa Alfabetización en la Edad Cierta (Paic), específicamente en el eje Evaluación, durante el año 2007, en la búsqueda de cumplir con una de sus metas prioritarias: ayudar a los municipios del Estado de Ceará a implementar sistemas municipales de evaluación. La estrategia de este programa fue iniciar las actividades por la evaluación de los alumnos, intentando crear un ambiente en el que el propio municipio conduciría todo el proceso de forma autónoma y, consecuentemente, tendría condiciones para conocer la realidad no sólo de la educación municipal sino también de todos sus alumnos, individualmente. De esta forma, el artículo presenta la metodología utilizada en la elaboración de los instrumentos que integran el protocolo de evaluación de 2007, y también, las acciones innovadoras desarrolladas en lo que se refiere a la difusión de los resultados. Las consecuencias esperadas de las acciones del programa ya han comenzado a ser detectadas por medio del gran compromiso y participación de los municipios en el transcurso de todo el proceso de evaluación y, sobretodo, de la intervención en la búsqueda de mejoras en la calidad de la educación.

Palabras clave: alfabetización, evaluación del desempeño, calidad de la enseñanza, Programa Alfabetización en la Edad Cierta (Paic).

\section{ABSTRACT}

The main purpose of this article is to present the activities developed by the Literacy at the Right Age Program (Paic), mainly in relation to Evaluation, during the year 2007, seeking to comply with one of its main goals: to help municipalities in the state of Ceará to introduce municipal evaluation systems. The program's strategy consisted in starting the activities by evaluating students, trying to create an environment in which the municipality itself would conduct the whole process autonomously, which in turn would offer it conditions to become acquainted with the reality not only of municipal education, but also of all its students individually. Therefore, this article introduces the methodology followed in preparing the instruments that constituted the 2007 evaluation protocol, as well as the innovative actions developed concerning the dissemination of the results. The expected consequences of the program have already begun to be detected through the municipalities' great commitment and involvement throughout the whole evaluation process and, above all, their interventions seeking improvements in education quality.

Keywords: literacy, evaluation of performance, education quality, Literacy at the Right Age Program (Paic). 


\section{INTRODUÇÃO}

Nos últimos anos, o Brasil tem presenciado a aplicação de inúmeras avaliações da educação escolar, as quais, posteriormente, divulgam resultados acusando a dramática insuficiência no desempenho dos alunos matriculados no ensino fundamental. Os dados das últimas séries do Sistema de Avaliação da Educação Básica (Saeb) mostram a crítica situação do analfabetismo de crianças que freqüentam a escola por quatro anos.

Especificamente no Estado do Ceará, os resultados revelaram que ao final da $4^{\text {a }}$ série do ensino fundamental $55 \%$ das crianças demonstraram ter competência abaixo do nível desejado (Brasil, 2004), apresentando graves dificuldades para ler e compreender textos simples, curtos e escritos na ordem direta.

Em 2004, a Assembléia Legislativa do Estado do Ceará, preocupada com o baixo desempenho de aprendizagem dos alunos do sistema público de ensino, instituiu o Comitê Cearense para a Eliminação do Analfabetismo Escolar. O Comitê foi constituído em parceria com o Fundo das Naçóes Unidas para a Infância (Unicef), União dos Dirigentes Municipais de Educaçáo (Undime/CE), Instituto Nacional de Estudos e Pesquisas Educacionais Anísio Teixeira (Inep/MEC) e Secretaria da Educação do Estado do Ceará (Seduc), contando também com a participação das principais universidades cearenses: Universidade Federal Vale do Acaraú (UVA), Universidade Regional do Cariri (URCA), Universidade Estadual do Ceará (UECE), Universidade Federal do Ceará (UFC) e Universidade de Fortaleza (Unifor). Os objetivos do Comitê foram: 1) realizar uma pesquisa para avaliar a aprendizagem da leitura e da escrita das crianças que estavam cursando a $2^{a}$ série do Ensino Fundamental nas escolas públicas de 48 municípios cearenses, 2) analisar como estava sendo realizada a formação do professor alfabetizador no Estado do Ceará, 3) observar a prática docente e as condiçóes de trabalho dos professores alfabetizadores em algumas escolas do Estado.

O diagnóstico revelou um quadro extremamente preocupante: 1) somente $40 \%$ dos alunos da amostra de quase 8.000 alunos foram considerados alfabetizados (Marques; Aguiar; Campos, 2005; Marques et al., 2006); 2) a maioria das universidades não possui estrutura curricular adequada para formar o professor alfabetizador; 3) a maioria dos professores náo tem metodologia para alfabetizar, abusa de cópias na lousa, e usa muito mal o tempo de aula que já é bastante reduzido.

Os dados do Relatório do Comitê Cearense para a Eliminação do Analfabetismo Escolar revelaram ainda que as gestóes municipais têm investido na estrutura física e nos equipamentos da rede pública de ensino. Contudo, esse investimento 
não resultava em melhoria da aprendizagem, pois dados do mesmo relatório demonstraram que somente $16 \%$ dos alunos matriculados no semestre inicial da $2^{\text {a }}$ série (atual $3^{\circ}$ ano) do Ensino Fundamental foram capazes de ler, compreender o texto lido e escrever pequenos textos.

O "desconhecimento" dessa realidade, pelos gestores municipais (prefeitos e secretários de educação), é agravado pela falta de uma política municipal de monitoramento da qualidade da educação oferecida às crianças. Ao contrário da estrutura física, que pode ser mais facilmente avaliada, a aprendizagem das crianças demanda um protocolo de avaliaçáo bem mais complexo, uma vez que busca avaliar algo que não é diretamente observável: o desenvolvimento cognitivo dos alunos. Ainda que tivéssemos, em 2004, dois processos, um nacional (Saeb) e outro estadual (Sistema Permanente de Avaliação da Educação Básica do Ceará - Spaece), avaliando a qualidade dos sistemas estaduais de ensino no Estado do Ceará, eles tinham como foco principal avaliar o resultado de ciclos de aprendizagem, ou seja, os alunos ao final do $5^{\circ}$ e $9^{\circ}$ anos do Ensino Fundamental e do $3^{\circ}$ ano do Ensino Médio.

É fato que a Lei de Diretrizes e Bases da Educação Nacional (Lei n. 9.394/96) atribui à Uniáo a responsabilidade de instituir um sistema nacional de avaliação do rendimento escolar, em regime de colaboração com os entes federados (art. 9o, inciso VI). Entretanto, essa configuraçáo se encontrava muito distante de produzir informaçóes de qualidade e em tempo real a respeito das unidades escolares e, sobretudo, das verdadeiras situaçóes dos alunos, não conseguindo exercer um impacto direto no cotidiano da escola.

A centralização de todo o processo avaliativo pelo governo federal, por intermédio do Inep, ou pelo governo estadual, através da Seduc, ao mesmo tempo em que viabiliza um processo avaliativo em dimensóes nacional e estadual, ocasiona pelo menos dois problemas. Primeiro, a realização de um processo avaliativo totalmente externo aos municípios acaba promovendo um aparente distanciamento dos professores, supervisores e diretores de escolas. Segundo, a "longa" demora em socializar os resultados da avaliação com os atores diretamente envolvidos no processo de ensino e aprendizagem em sala de aula agrava ainda mais esse distanciamento. Em ambos os casos, cria-se uma situação que dificulta sobremaneira a utilização dos resultados para promover intervençóes pedagógicas, visando à superação dos problemas desvelados pela avaliação.

A superação desse "distanciamento" da avaliaçáo da sala de aula e de seus principais atores poderia ser obtida se fossem implantados sistemas municipais 
para monitoramento da qualidade da educação que pudessem combater, de forma mais efetiva, o analfabetismo hoje presente em grande dimensão na rede pública de ensino.

Diante dessa realidade, em 2006, a Associação dos Prefeitos do Estado do Ceará (Aprece) e a Undime/CE, com o apoio do Unicef, assumiram o compromisso, com os municípios, de dar continuidade às açóes desenvolvidas pelo Comitê Cearense para a Eliminaçáo do Analfabetismo Escolar, dando origem ao Programa Alfabetização na Idade Certa (Paic). A participação de 60 municípios no referido programa ficou condicionada à assinatura de um pacto, no qual os prefeitos se comprometiam a priorizar a alfabetização das crianças nas séries iniciais. A idéia inicial era desenvolver açôes conjuntas em cinco áreas: avaliação da aprendizagem, gestão educacional, gestáo pedagógica, educação infantil e literatura infantil.

O nível de escolaridade definido pelo programa, em que o processo de alfabetização deve estar consolidado, foi o $2^{\circ}$ ano do Ensino Fundamental, o qual corresponde à antiga $1^{\text {a }}$ série ${ }^{1}$. Essa escolha se deu em função do reconhecimento de que melhorias substanciais e consistentes na qualidade do ensino fundamental, conforme aferido pelo Saeb ao final do $5^{\circ}$ e $9^{\circ}$ anos e do $3^{\circ}$ ano do Ensino Médio, somente poderão ser alcançadas por meio da implementação de mudanças estruturais nos anos iniciais do ensino fundamental, principalmente através da garantia de um ensino que privilegie o processo de alfabetização das crianças na idade adequada.

Quarenta e dois dos 60 municípios que ingressaram no Paic em 2006 avaliaram seus alunos matriculados no $2^{\circ}$ ano duas vezes no mesmo ano. Resultados positivos puderam ser constatados em alguns municípios participantes, pois grande parte deles conseguiu promover mudanças substanciais na proporção de alunos alfabetizados. O compromisso e envolvimento desses municípios rapidamente fizeram com que houvesse forte demanda para expandir as açóes desse programa nos demais municípios cearenses.

Em 2007, com a posse do atual governo do Estado do Ceará, a Secretaria de Educação do Estado resolveu oferecer todas as condiçóes, logísticas e financeiras, necessárias para atender a todos os municípios cearenses. Esse esforço foi prontamente correspondido, porque resultou na adesão de todos os municípios do Estado.

${ }^{1}$ De 2006 em diante, as escolas municipais começaram a oferecer o ensino fundamental a crianças a partir de seis anos de idade, em razão da promulgação da Lei n. 11.114/05. Dessa forma, a duração desse nível de ensino foi ampliada de oito para nove anos. 
Dessa forma, o Estado do Ceará foi pioneiro na implementação das açôes do Paic focadas em cinco eixos: 1) Avaliação da aprendizagem, 2) Gestão educacional, 3) Alfabetização, 4) Educação infantil, 5) Literatura infantil.

A estratégia desse programa foi iniciar as atividades pela avaliação dos alunos, buscando criar um ambiente em que o próprio município conduzisse todo o processo de forma autônoma e, conseqüentemente, tivesse condiçóes para conhecer a realidade não apenas da educação municipal como também de todos os seus alunos, individualmente.

É nesse contexto que este artigo está inserido, tendo como objetivo principal apresentar as atividades desenvolvidas pelo Paic, especificamente no eixo de Avaliação, durante o ano de 2007, na busca de cumprir com uma de suas metas prioritárias: ajudar os municípios participantes a implantar sistemas municipais de avaliação. O cumprimento dessa meta possibilitará a difusão da cultura de avaliação entre gestores municipais de educação, coordenadores pedagógicos e professores, tornando possível não somente planejar e executar as avaliaçóes de forma autônoma como também utilizar os resultados para promover mudanças qualitativas na educação do Estado do Ceará.

\section{A METOdOLOGIA DE AVALIAÇÃO DO PAIC}

O desenvolvimento do protocolo de avaliaçáo, utilizado pelos municípios em 2007, tomou como referência maior os princípios propostos pelo The Joint Committee on Standards for Educational Evaluation (1994), responsável pela proposição de padróes de excelência para avaliação educacional. Marques, Aguiar e Campos (2007) discorreram sobre a concepção do Paic, os primeiros resultados e as perspectivas da avaliação propostas pelo programa, oportunidade em que revelaram a preocupação em se desenvolver um processo avaliativo que obedecesse à utilidade, viabilidade, precisão e ética. A observância a esses princípios levou à construção de um protocolo de avaliação fortemente direcionado à tomada de decisão, com aplicação externa à escola, de caráter formativo, de amplitude censitária e alcançando todos os alunos (larga escala).

A concepçáo de avaliação adotada pelo Paic está pautada no campo teórico proposto por Cronbach (1982) e Scriven (1967). Do primeiro autor, concebeu-se a idéia de que a avaliação serve para uma tomada de decisão e não somente para divulgar dados sobre determinada situação. Metodologicamente, Cronbach propóe que uma avaliaçáo deve incluir: 1) estudos do processo; 2) medidas de rendimento e 3) estudos de seguimento, isto é, o caminho posterior seguido pelos estudantes que par- 
ticiparam do programa (Escudeiro, 2003). De Scriven (1967), absorveu-se a forte ênfase no caráter formativo, de tal forma que todo o esforço avaliativo pudesse ser utilizado pelos supervisores e professores para a melhoria do trabalho pedagógico realizado na escola.

A necessidade de se implementar sistemas municipais de avaliação nos levou a estruturar uma avaliação do tipo externa.A palavra externa é utilizada para designar que a avaliação é conduzida por agentes externos à escola, que no presente programa são técnicos capacitados pelas secretarias de educação dos municípios, ficando vedada a participação de professores das escolas avaliadas.

Para realmente alcançar o êxito esperado, além de externa a avaliação deveria ser censitária e de larga escala. Sendo censitária, alcançaria todas as crianças matriculadas no $2^{\circ}$ ano do Ensino Fundamental dos municípios participantes, oferecendo informaçóes valiosas sobre o estágio de desenvolvimento em que cada criança se encontra e possibilitando, conseqüentemente, o planejamento de intervençóes pedagógicas para cada criança.

Sendo de larga escala, envolveria "uma ação cooperativa entre técnicos e especialistas visando à superação de problemas” (Vianna, 2005, p. 129) de toda a rede municipal. Em virtude de sua dimensão, uma avaliação de larga escala demanda experiência, uma estrutura básica de funcionamento, controle gerencial e monitoramento (idem, 2005, p. 130). Dessa forma, as instituiçóes citadas anteriormente operam em regime de natureza sistêmica para garantir o êxito do programa.

Com base nessa fundamentação, pode-se dizer que a avaliação proposta pelo Paic tem como propósito principal melhorar a qualidade do processo de aprendizagem, pois seus resultados serão verdadeiros nortes para as intervençóes pedagógicas a serem conduzidas pelo eixo de Alfabetização. Assim, a idéia que concebe o tipo de avaliação proposto pelo programa encontra respaldo na opinião de Cardinet, 1989 (apud Condemarín; Medina, 2005, p.13)

[...] mais do que medir ou julgar uma experiência de aprendizagem, a avaliaçáo permite intervir a tempo para assegurar que as estratégias e os meios utilizados na formação respondam aos objetivos propostos, às características dos alunos e ao contexto no qual ocorre a aprendizagem, para que a experiência seja bem sucedida.

\section{O PROTOCOLO DE AVALIAÇÃO}

Um dos maiores desafios para a implantaçáo de sistemas municipais de avaliação é construir um ambiente de cooperação que propicie a efetiva participação das 
equipes das secretarias municipais em todas as etapas do processo. Para tanto, foi necessário criar um protocolo de avaliação que pudesse ser apropriado e utilizado pelos municípios.

O protocolo disponibilizado aos 184 municípios do Estado do Ceará continha os seguintes componentes: 1) cadernos de avaliação, 2) roteiro de aplicação, 3) manual de orientaçóes para o aplicador, 4) manual de orientação para análise da parte escrita, 5) fichas de controle do trabalho realizado na turma, 6) sistema para registrar as informaçôes da avaliação e imprimir os resultados, 7) manual de instalação desse sistema, e 8) manual de orientaçóes para digitação e envio das bases de dados.

Toda a documentaçáo foi organizada em forma de manuais e disponibilizada às secretarias municipais nas versóes impressa (entregues durante os treinamentos e oficinas) e digital (no site www.idadecerta.seduc.ce.gov.br). A fim de manter o sigilo de toda a documentação, os municípios foram cadastrados no sistema com uma senha de acesso.

\section{A ELABORAÇÃO DO INSTRUMENTO DE AVALIAÇÃO}

Três desafios foram apresentados durante a elaboração do instrumento de avaliação.

O primeiro, e o maior deles, referia-se à escolha dos descritores que permitissem construir um instrumento para avaliar desde as habilidades mais básicas do processo de alfabetização, como, por exemplo, a aquisiçáo do sistema de escrita até as habilidades mais complexas de leitura e escrita, incluindo a produçáo textual. Esse desafio resultou na necessidade de se escolher, dentre um amplo conjunto de descritores de uma matriz de referência, um subconjunto de descritores que tornasse possível elaborar uma avaliação com essa característica.

Dessa forma, iniciaram-se as atividades com a seleção das competências e habilidades a serem avaliadas. Como o Estado do Ceará ainda não possuía uma matriz de referência ${ }^{2}$ em nível de alfabetização, foi utilizada para a construção do instrumento de avaliação a Matriz de Alfabetização do Ceale ${ }^{3}$. A seleção dos

2 Ainda em 2007, as equipes de avaliação do Paic e da Seduc/CE, com apoio de especialistas do Ceale/UFMG e Caed/UFMG, elaboraram a matriz de referência da alfabetização.

3 O Ceale desenvolve projetos institucionais e interinstitucionais de pesquisa sobre a alfabetização e o letramento no país. Os pesquisadores do Ceale compóem o núcleo de pesquisa Educação e Linguagem do Programa de Pós-Graduação Conhecimento e Inclusão Social (mestrado e doutorado) da Faculdade de Educação da UFMG. 
descritores foi realizada em uma oficina que contou com a participação de técnicos da Secretaria de Educação do Estado do Ceará (Seduc), de especialistas em alfabetização, lingüística, fonoaudiologia e avaliação educacional do Núcleo de Avaliação Educacional do Programa de Pós-Graduação da Universidade Federal do Ceará. De posse dos descritores selecionados, foram realizadas diversas oficinas para a elaboração, análise e seleção de itens para compor a atividade de avaliação. Esse trabalho foi concluído com a entrega da proposta do instrumento de avaliação (prova ou teste) a ser pré-testado.

O segundo desafio apresentado referia-se à dificuldade de avaliar alunos que ainda não seriam capazes de ler e compreender frases. Essa preocupação surgiu quando se pensou que o aluno poderia deixar de responder a alguns itens não porque não dominasse aquela habilidade, mas porque não dominava ainda a leitura de frases, estruturas comuns aos enunciados dos itens. Diante disso, houve a necessidade de se pensar em um tipo de instrumento cujos enunciados dos itens fossem total ou parcialmente lidos pelos aplicadores, além daqueles em que o aluno deveria ler sozinho.

O terceiro desafio girou em torno da necessidade de desenvolver uma avaliação que pudesse conciliar as características de uma proposta formativa com as restriçóes de uma avaliação censitária.

Em consonância com a determinação de envolvimento efetivo dos técnicos das secretarias municipais, e preocupados em manter o rigor na aplicação do instrumento, foi necessário desenvolver um trabalho criterioso de planejamento das açóes a serem conduzidas durante a avaliaçáo. Incluiu-se a produção de um DVD mostrando o passo-a-passo da aplicação do protocolo de avaliação, bem como a elaboração de um roteiro para a condução da avaliação em sala de aula contendo todas as falas que obrigatoriamente deveriam ser proferidas.

O trabalho seguinte à elaboração dos itens e do roteiro de aplicação foi a pré-testagem $^{4}$ do instrumento. Segundo Vianna (2005, p.133), "Uma avaliação, qualquer que seja a natureza, demanda a pré-testagem dos instrumentos, a fim de adequá-los aos sujeitos integrantes do conjunto avaliado. Isso, naturalmente, exige que se tenha uma amostra representativa [...]". Assim, a pré-testagem envolveu toda a equipe do eixo de avaliaçáo do Paic que contou com a colaboraçáo de dois municípios cea-

${ }^{4}$ No campo da estatística, um pré-teste é a aplicação do instrumento, na sua versão preliminar, a uma amostra de indivíduos, tendo por objetivo identificar problemas que justifiquem uma modificação da redação, alteração do formato, ou mesmo serem eliminadas da versão final. 
renses, Pacatuba e Maranguape. A equipe contabilizou a aplicação do pré-teste em cerca de 700 alunos. É importante destacar que profissionais das próprias secretarias municipais também participaram da aplicação, pois o intuito era também testar o roteiro de aplicação. Após a aplicação, a equipe, ainda in loco, procurou ouvir as sugestóes das aplicadoras, que tiveram grande valia na reestruturação dos instrumentos.

As respostas dos alunos no pré-teste foram analisadas utilizando-se a Teoria Clássica de Testes (TCT). Foram calculados os índices de dificuldade (porcentual de acerto), índice de discriminação (diferença do porcentual de acerto entre os grupos de alunos com melhor e com pior desempenho) e correlação bisserial entre o escore total do teste e o item. O resultado dessa análise foi utilizado para a realização de pequenos ajustes nos itens e no roteiro de aplicação, o que culminou com a disponibilização da versão final do protocolo de avaliação 2007.

\section{O INSTRUMENTO DE AVALIAÇÃO}

O instrumento de avaliação, ou caderno de avaliação, utilizado no Paic em 2007, constituiu-se de um bloco de oito páginas, contendo a capa e as questóes propriamente ditas, as quais foram divididas em três partes. Para evitar que os alunos pudessem copiar as respostas dos colegas, provocando uma visão distorcida da realidade, as alternativas dos itens de múltipla escolha tiveram sua seqüência alterada, gerando três cadernos de avaliaçáo de tipos 1, 2 e 3. Essa alteração náo implicou mudança de qualquer um dos enunciados, possibilitando que o aplicador manipulasse o mesmo roteiro de aplicaçáo para todos os tipos de cadernos.

A primeira página (capa) continha campos que deveriam ser preenchidos pelo aplicador acerca das informaçóes do município, da escola, da turma e do turno. Logo abaixo desses campos, havia espaço para o registro de informaçóes sobre o aluno: código, nome, idade, sexo, se era portador de NEE e se realizou ou não a atividade. Essa mesma página possuía duas grades para registro dos gabaritos. Na primeira, o aplicador transcrevia o gabarito das 35 questóes, e, na segunda, registrava os códigos referentes à análise das questóes da parte escrita, segundo as orientaçóes do manual específico para esse fim.

A primeira parte da avaliação tinha questóes relacionadas com o sistema de apropriação da escrita. Da página 2 até a metade da página 5 foram abordadas questóes de múltipla escolha. Como se tratava de um instrumento a ser aplicado a alunos, em sua grande maioria de 7 anos de idade, buscou-se organizá-lo de forma atrativa, lúdica e não cansativa. Por isso, utilizou-se grande variedade de figuras, e os pró- 
prios itens eram localizados pela presença de um personagem e não pelo número das questôes como, comumente, se vê. Para ilustrar, observe a fala do aplicador para um dos itens: "Crianças, vamos iniciar com a atividade da boneca Emília do Sítio do Pica Pau Amarelo. Vocês estão vendo a Emília ao lado do quadro? [pequena pausa] Muito bem! Marque com um X os quadrinhos que têm apenas letras". Esse procedimento, além de ser um agradável incentivo, afastou a possibilidade de o aluno não fazer a atividade ou confundir-se na seqüência dos itens por ter dificuldades em identificar os números. Adicione-se, ainda, que as questóes utilizadas para avaliar as habilidades iniciais do processo de alfabetizaçáo tinham enunciados lidos pelo aplicador, possibilitando que todos os alunos participassem dessa parte da avaliação.

A segunda parte da avaliaçáo continha questóes relacionadas com a escrita, e envolvia: escrita de letras, do nome, de palavras, de frase e de texto. Na escrita de letras, o aplicador ditou algumas letras que foram previamente escolhidas levando em consideração critérios específicos. Na escrita do nome, foi solicitado que o aluno escrevesse seu nome da maneira como soubesse. Nesse caso, foi verificado se a escrita produzida correspondia (ou se aproximava) do nome ou de parte do nome. A análise da escrita das quatro palavras foi realizada adotando parcialmente a Escala de Escrita proposta por Ferreiro e Teberosky (1985), a qual permite diferenciar os níveis de desenvolvimento da escrita. Já na escrita da frase, foi considerada a existência ou não do espaçamento entre as palavras (segmentação). Em relação ao texto produzido pelo aluno, buscou-se avaliar se era um texto verbal com pelo menos uma oração e se possuía sentido, isto é, se estava de acordo com o que foi solicitado na avaliação. Os textos que preencheram esses requisitos eram reavaliados nos seguintes aspectos: encadeamento lógico, representação gráfica apoiada ou não na oralidade, pontuação, uso de letras maiúsculas e minúsculas, ortografia e número de palavras do texto.

A terceira parte da avaliação continha os itens relacionados com o eixo de leitura propriamente dito. As questóes distribuíram-se nas páginas 7 e 8 do caderno de avaliação e, nessa parte, o aplicador náo lia os enunciados. $\mathrm{O}$ aluno foi orientado a fazer as questóes sem ajuda. Essa etapa avaliou as habilidades de leitura, com compreensão, de frases e textos.

\section{O PROCESSO DE ANÁLISE DA PRODUÇÃO ESCRITA E DIVULGAÇÃO DOS RESULTADOS}

De acordo com a concepção de avaliação apresentada pelo Paic, o processo de análise da produçáo escrita e a divulgaçáo dos resultados deveriam ser conduzidos pelas equipes municipais, sob a supervisão do grupo de especialistas do eixo de ava- 
liação. Essa é uma das condiçôes indispensáveis para a implementação de sistemas municipais de avaliação.

Considerando que as orientações gerais e as rotinas necessárias, para organizar a avaliação e aplicar os instrumentos de avaliação, foram devidamente documentadas em um manual e em um DVD, restava-nos propor uma estratégia para analisar a produção escrita dos alunos.

Por se tratar de um processo a ser conduzido por diversos especialistas das secretarias municipais de educação, era necessário ter alguma proposta para manter o rigor na análise da parte escrita. Assim, a equipe do eixo de avaliação do Paic elaborou um documento bastante detalhado contendo os seguintes elementos: 1) breves explicaçôes teóricas sobre cada aspecto a ser avaliado, 2) códigos para cada critério, 3) exemplos reais de todas as situaçóes descritas, 4) exercícios para serem feitos durante a oficina de treinamento, e 5) tabela contendo todos os códigos de todos os aspectos que foram avaliados. Essa iniciativa teve como objetivo maior padronizar, ao máximo, a análise da produção escrita para que os resultados sofressem o mínimo de interferências advindas do comportamento do aplicador.

Realizada a aplicação e a adequada análise da parte escrita, por técnicos das secretarias municipais de educação, chegou-se ao momento de consolidar o resultado da avaliação. Visando a facilitar o processo de digitação das informaçóes, análise dos resultados e impressão dos resultados alcançados, um software foi distribuído a todos os 184 municípios do Estado do Ceará. Técnicos da própria secretaria de educação digitavam as informações, verificavam se elas estavam corretamente digitadas e imprimiam os seguintes relatórios: 1) Resultado geral da avaliação em nível do Estado, 2) Resultado geral da avaliação por município, 3) Resultado por escola, 4) Resultado da turma por descritor, 5) Resultado por turma e por aluno nas dimensões leitura e escrita, 6) Resultado por turma e por aluno na dimensão leitura, e 7) Resultado por turma e por aluno na dimensão escrita.

Essa etapa trouxe uma natural ansiedade pela rápida divulgaçáo dos resultados, revelando que "[...] esse é um momento crítico no processo e em seu gerenciamento. Apesar da informatização, há a possibilidade de erros humanos, impondo-se revisões e verificação da consistência dos resultados" (Vianna, 2005, p. 132). Por esse motivo, os municípios enviavam a base de dados à coordenação geral do eixo de avaliação do Paic para que se pudesse verificar a consistência das informaçóes e consolidar uma base de dados em nível estadual.

Com o intuito de potencializar a utilizaçáo dos resultados da avaliação para promover intervençóes pedagógicas, a equipe do eixo de avaliaçáo trabalhou in- 
tensivamente para auxiliar as secretarias municipais de educação a compreender os resultados. Para isso, foi organizado um encontro com os gerentes regionais, supervisores e técnicos das Coordenadorias Regionais de Desenvolvimento da Educação (Crede) e das secretarias municipais de educação.

Em razão do elevado número de participantes (aproximadamente 500), os municípios foram distribuídos em seis macrorregióes. As atividades desse encontro foram organizadas de tal forma que cada técnico municipal participasse de dois momentos. O primeiro momento, conduzido em um auditório, foi para divulgar informes gerais dos eixos de alfabetização e avaliaçáo. No segundo momento do encontro, em forma de oficina, com a divisáo dos participantes em três ou quatro subgrupos, foram apresentados os relatórios, seguidos de discussóes a respeito dos resultados por aluno, referentes aos eixos da escrita e leitura, bem como os resultados por descritor.

Essa organização permitiu que todos os integrantes participassem das mesmas atividades sem prejuízo de informaçóes e tendo um acompanhamento mais individualizado. Outro aspecto que possibilitou essa aproximação foi a participação tanto do grupo responsável pela elaboração e pré-testagem do instrumental de avaliação quanto do grupo de tutores do eixo de alfabetização, enriquecendo sobremaneira as discussóes com a aproximação da parte técnica da avaliaçáo com a parte pedagógica.

Terminado o estudo dos relatórios, foi solicitado ao grupo que fizesse uma simulação de análise dos resultados, procurando entender, na prática, os números encontrados. Para finalizar, os participantes se manifestaram explicando os casos analisados, inclusive fazendo referência à grande contribuição que o entendimento dos dados iria dar às intervençôes pedagógicas.

\section{CONSIDERAÇÕES FINAIS}

A instituição do Ensino Fundamental de nove anos, antecipando a entrada do aluno na escola, exigiu, dentre outras coisas, a urgente revisão das propostas de alfabetização desde a organização curricular das práticas de ensino até as formas de avaliação.

O percurso trilhado pelo Programa Alfabetização na Idade Certa vem mostrando a grande contribuição no repensar sobre o processo de alfabetização. O programa, como dito anteriormente, não se restringe à simples divulgação dos resultados no nível em que náo se pode fazer mais nada retroativamente. $\mathrm{O}$ sistema de avaliaçáo proposto pelo programa tem caráter diagnóstico e, sobretudo, formativo, permitindo que sejam detectadas as dificuldades dos alunos a tempo de se fazer intervençôes significativas. 
Vale destacar que a elaboração da avaliação teve como parâmetro norteador a necessidade de oferecer informaçóes que realmente pudessem ser úteis para o processo de intervenção pedagógica. De fato, a forma como os resultados foram organizados concede uma visão bem mais aprofundada das habilidades que já foram consolidadas, as que estão em processo de consolidação e aquelas que ainda não foram consolidadas. Isso permite que a intervenção aconteça exatamente quando o aluno demonstrou dificuldade. Observa-se que os resultados da avaliação da escrita podem, por exemplo, mostrar que determinado aluno escreve com encadeamento lógico, apoiado na escrita alfabética ortográfica, mas ainda não utiliza os sinais de pontuação adequadamente, tampouco as letras maiúsculas e minúsculas. Esta informação sinaliza em que pontos, especificamente, a professora deve intervir.

Outro aspecto fundamental dessa experiência se refere ao fortalecimento das equipes permanentes das secretarias municipais de educação. Cada município constituiu suas equipes de aplicadores, avaliadores, digitadores e gerentes para atuarem nas atividades do eixo de avaliação do Paic. Com isso, iniciou-se um caminho de cooperação, compromisso e autonomia trilhado pelos principais envolvidos no processo. Esse caminho é descrito por Vianna (2005, p.133) da seguinte maneira: “[...] um programa de avaliação resulta da cooperação e da interação de diferentes capacidades e diversos tipos de vivências".

Visando a promoção desse fortalecimento técnico-pedagógico, a equipe do eixo de avaliação não se limitou em elaborar e divulgar os manuais de procedimentos. Houve diversos momentos anteriores à aplicação em que foram discutidos e explorados todos os documentos de orientaçôes. Perseguindo o enfoque de construir a autonomia dos municípios no que se refere aos processos avaliativos, a equipe promoveu seminários, palestras e oficinas com os técnicos das secretarias municipais e gerentes municipais para que pudessem levar as informaçóes partilhadas e disseminá-las nas próprias equipes.

Vale ressaltar que nenhuma proposta de avaliação, atualmente realizada no Brasil, chega ao nível de detalhamento, rapidez na divulgação de resultados e envolvimento e cooperação dos atores, tal qual o Paic proporciona. Esse é o grande diferencial do programa e, sem dúvida, é o que tem feito surgir um ambiente de compromisso e responsabilidade já sentido nos diversos momentos em que o eixo de avaliação esteve junto dos municípios cearenses.

Esses momentos foram extremamente significativos para que a equipe do Paic sentisse que estava no caminho certo. Teve-se, acerca do trabalho do programa, uma espécie de feedback oriundo dos próprios sujeitos que compunham o processo. 
Isso legitimou a certeza de que os planos, as açóes e os resultados têm mais êxito se todos estiverem envolvidos.

Em vários encontros com os representantes dos municípios cearenses, foram relatadas experiências que validaram o que se disse anteriormente. "As avaliaçóes foram muito positivas. O que eu mais destaco é a chamada para a responsabilidade dos professores. Com os resultados, nós fizemos um relatório qualitativo de cada escola" (Iguatu); "Senti que foi um momento rico, pois despertou a responsabilidade do professor em chegar ao ideal. A avaliação deu uma informação mais real. Elaboramos um relatório por escola, sentamos com o núcleo gestor e tomamos as medidas urgentes" (Icapuí); "O professor estava acomodado em achar que o problema estava no aluno. A intervençáo trabalhou o professor tentando despertar o seu senso de responsabilidade" (Cedro); "Serviu para avaliar muita coisa, não só a criança, mas o trabalho pedagógico e o da Secretaria. A atuação do Paic é realmente pedagógica" (Jaguaribe).

Com base nesses breves relatos, fica a certeza de que o Programa Alfabetizaçáo na Idade Certa - Paic - é, sem dúvida, o pioneiro na implantação e gerenciamento de um processo de avaliação que visa, sobretudo, à construção da autonomia dos municípios cearenses no diagnóstico e intervenção para a melhoria da qualidade da educação.

\section{REFERÊNCIAS BIBLIOGRÁFICAS}

AGUIAR, R. R.; CAMPOS, M. O. C.; GOMES, I. F. (Org.). Relatório do Comitê Cearense para eliminação do analfabetismo escolar. Fortaleza: Assembléia Legislativa do Estado do Ceará, 2006.

BRASIL. Lei de Diretrizes e Bases da Educação Nacional n. 9.394, de 1996. Brasília, 1996.

BRASIL. Ministério da Educação. INEP. Resultados do SAEB 2003. Brasília, 2004.

CEREJA, W. R.; MAGALHÃES, T. C. Gramática, texto, reflexão e uso. São Paulo: Atual, 2004.

CONDEMARÍN, M.; MEDINA, A. Avaliação autêntica: um meio para melhorar as competências em linguagem e comunicação. Tradução: Fátima Murad. Porto Alegre: Artmed, 2005.
CRONBACH, L. J. Designing evaluations of educational and social programs. Chicago: Jossey-Bass, 1982.

ESCUDERO, T. Desde los tests hasta la investigación evaluativa actual: un siglo, el XX, de intenso desarrollo de la evaluación en educación. Revista Electrónica de Investigación y Evaluación Educativa, v. 9, n. 1., 2003. Disponível em: http:<//www.uv.es/RELIEVE/ v9n1/RELIEVEv9n1_1.htm>

FERREIRO, E.; TEBEROSKY, A. Psicogênese da língua escrita. Tradução: Diana Myrian Lichtenstein; Liana Di Marco; Mário Corso. Porto Alegre: Artes Médicas, 1985.

INFANTE, Ulisses.Dotexto ao texto:curso prático de leitura e redação. São Paulo: Scipione, 1991. 
KOCH, I. V.; VILLAÇA. G. A Coesão textual. São Paulo: Contexto, 1989.

MARQUES, C. A.; AGUIAR, R. R.; CAMPOS, M. O. C. Avaliação do nível de alfabetização das crianças matriculadas na $2^{a}$ série das escolas públicas do estado do Ceará. In: CONGRESSO INTERNACIONAL EM AVALIAÇÃO EDUCACIONAL, 2, 2005, Fortaleza. Anais... Fortaleza: EdUFC, 2005.

. Programa alfabetização na idade

certa: concepções, primeiros resultados e perspectivas. In: REUNIÃO DA ABAVE, 3, 2007, Belo Horizonte. Anais... Belo Horizonte, 2007.

MARQUES, C. A. et al. Qual o nível de alfabetização das crianças do Ceará? In: AGUIAR, R. R.; GOMES, I. F.; CAMPOS, M. O. C. 2005.
(Org.). Relatório final do comitê cearense para a eliminação do analfabetismo escolar: educação de qualidade começando pelo começo. Fortaleza: Assembléia Legislativa do Ceará, 2006.

OLIVEIRA, D. P. T. de. Avaliação externa do ciclo básico: diagnóstico necessário à melhoria da qualidade da educação. Ensaio: Avaliação e Políticas Públicas em Educação, v. 6, n. 18, p. 67-84, jan./mar. 1998.

SCRIVEN, M. S. The Methodology of evaluation. In: TYLER, R. W.; GAGNE, R. N.; SCRIVEN, M. S. Perspectives of curriculum evaluation. Chicago: Rand McNally, 1967. p.39-83.

VIANNA, H. M. Fundamentos de um programa de avaliação educacional. Brasília: Líber Livro,

Recebido em: outubro 2008

Aprovado para publicação em: novembro 2008 